\title{
Hemodialfiltración on line vs hemodiálisis de alto flujo: influencia sobre la anemia
}

\author{
Elena Martín García, María Uguet Canal, Montserrat Arribas Charfolé, Jacoba Rodríguez Peña
}

Hospital Ramón y Cajal. Madrid

\section{Introducción:}

La influencia de las técnicas convectivas sobre la evolución de la anemia del enfermo dializado es un tema controvertido sobre todo cuando se compara con la hemodiálisis realizada con membrana de alto flujo y baño ultrapuro. En muchos trabajos no se consigue objetivar un beneficio a corto plazo.

\section{Objetivo:}

Comparar los valores de hemoglobina y la necesidad de eritropoyetina en pacientes dializados con hemodiafiltración online frente a los pacientes dializados con hemodiálisis con membrana de alto flujo.

\section{Material y métodos:}

Estudiamos la evolución de la anemia en los enfermos de nuestra unidad, se trata de 11 enfermos con edad $68 \pm 20$ años que han recibido tratamiento con hemodia- filtración "on line" postdilucional (HDF-OL) de forma ininterrumpida durante un mínimo de 18 meses. Como grupo control hemos analizado la evolución de los enfermos que durante el mismo periodo de tiempo fueron tratados exclusivamente con hemodiálisis, en este grupo entran 16 enfermos con edad $72 \pm 14$ años, con membrana de alto flujo y baño ultrapuro (HD-AF).

\section{Resultados:}

La concentración de hemoglobina se mantuvo estable en ambos grupos durante el estudio. Aunque el grupo con HD-AF partía con una concentración menor de hemoglobina, no hubo diferencia estadísticamente significativa entre ambos grupos en ningún momento de la evolución. En el grupo de HDF-OL la dosis semanal de eritropoyetina comenzó a disminuir a partir del sexto mes de tratamiento, pero el descenso solo alcanzó significación estadística a los 18 meses, momento en el cual 5 de los 11 enfermos no precisaban eritropoyetina. En el grupo de HD-AF la dosis de eritropoyetina no sufrió variaciones significativas, y no se pudo retirar en ninguno de los enfermos. Al comparar ambos grupos, la

\begin{tabular}{|c|c|c|c|c|c|c|c|}
\hline \multicolumn{7}{|c|}{ Grupo HDF-OL } \\
\hline & Basal & 3 meses & 6 meses & 9 meses & 12 meses & 15 meses & 18 meses \\
\hline Hb g/dl & $12 \pm 0,8$ & $11,5 \pm 0,9$ & $12,2 \pm 1,4$ & $12 \pm 1,2$ & $12 \pm 1,1$ & $11,9 \pm 1,4$ & $11,8 \pm 1,3$ \\
\hline $\begin{array}{c}\text { EPO UI/se- } \\
\text { mana }\end{array}$ & $5705 \pm 5432$ & $5864 \pm 4754$ & $4682 \pm 3642$ & $4364 \pm 4817$ & $3909 \pm 4283$ & $3227 \pm 3517$ & $2432 \pm 3256^{*}$ \\
\hline
\end{tabular}

${ }^{*} \mathrm{p}<0,05$ con respecto a basal

\begin{tabular}{|c|c|c|c|c|c|c|c|}
\hline \multicolumn{7}{|c|}{ Grupo HD Alto flujo } \\
\hline Hb g/dl & $11,2 \pm 1,5$ & $11,3 \pm 0,9$ & $11,7 \pm 0,8$ & $11,5 \pm 0,8$ & $11,3 \pm 1,2$ & $11,1 \pm 1$ & $11 \pm 0,9$ \\
\hline $\begin{array}{c}\text { EPO UI/se- } \\
\text { mana }\end{array}$ & $7563 \pm 3596$ & $7844 \pm 4057$ & $7969 \pm 3663$ & $7781 \pm 4301$ & $8219 \pm 4665^{*}$ & $7938 \pm$ & $4312^{* *}$ \\
\hline
\end{tabular}

${ }^{*} p<0,05 ; p<0,01$ con respecto a grupo HDF-0L 
diferencia en la dosis de eritropoyetina comenzó a ser estadísticamente significativa a partir de los 12 meses de tratamiento con HDF-OL.

\section{Conclusión:}

En nuestra experiencia, el efecto de la convección sobre la anemia comienza a detectarse a partir del $6^{\circ}$ mes (en el cual comienza a disminuir el tratamiento semanal de eritropoyetina) y alcanza significación a partir del mes 12 (más de la mitad de los enfermos dejan de precisar eritropoyetina). Con periodos de evolución más cortos pueden no detectarse efectos relevantes.

\section{Referencias Bibliográficas}

1. Teruel JL. Convección versus difusión: ¿ha llegado el momento del cambio? Nefrología 2009;29:594603.

2. Peña Ortega $M$, Mañero Rodríguez $C$, Fernández López P, Prados Garrido MD, Polo Moyano A, Palma Barrio R, et al. Estudio comparativo de los requerimientos de factores eritropoyéticos en pacientes tratados con hemodiafiltración "on-line" frente a diálisis convencional. Nefrología 2010;30 Suppl 1:89. 